\title{
Válvulas redutoras de ar nos sistemas de micromedição nas redes de distribuição de água
}

Nos sistemas de micromedição nas redes de distribuição de água tratada podem existir algumas falhas, entre elas está o fato da passagem do ar pelo hidrômetro e sua respectiva contabilização do fluido como se fosse água. Baseado nessa questão, o presente estudo tem como objetivo analisar a interferência do ar na micromedição verificando a eficácia das válvulas redutoras de ar como aparelhos que possam minimizar ou extinguir a passagem do ar pelo hidrômetro e consequentemente as cobranças indevidas por parte das concessionárias. A água que chega às torneiras de milhares de famílias, indústrias e comércios, passa po uma série de processos até o produto final. Nesse contexto, percebe-se o quão é importante o trabalho das empresas responsáveis pelo tratamento e distribuição da água, onde o papel delas é garantir a qualidade da água e posteriormente a sua chegada às torneiras de cada consumidor. Porém, nem sempre é o que acontece diversos fatores podem comprometer a distribuição da água, gerando imprecisões na micromedição e prejuízos para os usuários, pois estes pagam por ar ao invés de água. A metodologia aplicada neste projeto de pesquisa realizou ensaios laboratoriais que foram feitos no laboratório de hidráulica do Instituto Tocantinense Presidente Antônio Carlos Porto (ITPAC, PORTO), onde, através dos experimentos laboratoriais foi simulado a micromedição de um sistema de distribuição residencial de água, juntamente com a instalação da válvula redutora de ar, e injeção de ar comprimido através de um aparelho compressor de ar simulando de forma monitorada a passagem de ar pelos aparelhos medidores (hidrômetros). Depois do trabalho concluído espera-se que os resultados obtidos possam somar como esclarecimentos em relação a presença de ar nos sistemas de distribuição de água e que os aparelhos estudados possam mostrar eficiência em relação a diminuição ou até mesmo a inibição da marcação do ar nos hidrômetros.

Palavras-chave: Ar; Válvulas; Pressão; Micromedição.

\section{Air reducing valves in micro-measurement systems in water distribution networks}

\begin{abstract}
In the micro-measurement systems in the treated water distribution networks, there may be some flaws, among them is the fact of the air passing through the hydrometer and its respective accounting of the fluid as if it were water. Based on this issue, the present study aims to analyze the interference of air in the micromeasurement by verifying the effectiveness of air reducing valves as devices that can minimize or extinguish the passage of air through the hydrometer and, consequently, the undue charges by the concessionaires. The water that reaches the taps of thousands of families, industries and businesses goes through a series of processes until the final product. In this context, it is clear how important the work of the companies responsible for the treatment and distribution of water is, where their role is to guarantee the quality of the water and subsequently its arrival at the taps of each consumer. However, this is not always the case, severa factors can compromise the distribution of water, generating inaccuracies in micro-measurement and losses for users, as they pay for air instead of water. The methodology applied in this research project carried out laboratory tests that were carried out in the hydraulic laboratory of the Tocantinense President Antônio Carlos Porto Institute (ITPAC, PORTO), where, through laboratory experiments, the micro-measurement of a residential water distribution system was simulated, together with the installation of the air reducing valve, and injection of compressed air through an air compressor device, simulating, in a monitored way, the passage of air through the measuring devices (hydrometers). After the work is completed, it is expected that the results obtained can add up as clarifications regarding the presence of air in the water distribution systems and that the studied devices can show efficiency in relation to the reduction or even the inhibition of the air marking in the hydrometers.
\end{abstract}

Keywords: Air; Valves; Pressure; Micromeasurement.

Topic: Engenharia de Recursos Hídricos

Reviewed anonymously in the process of blind peer.

Romerito Avelino dos Santos (iD)

Faculdade Presidente Antônio Carlos, Brasi

http://lattes.cnpq.br/4714372711867963

http://orcid.org/0000-0002-6352-144X

avelino69engcivil@gmail.com

Ângelo Ricardo Balduino (D)

Instituto Tocantinense Presidente Antônio Carlos, Brasil

http://lattes.cnpq.br/8475669590774317

http://orcid.org/0000-0002-7082-2566

angelo@ifto.edu.br

Claudia Corrêa de Paula (it

Faculdade Presidente Antônio Carlos, Brasil

http://lattes.cnpq.br/7841387730857363

http://orcid.org/0000-0002-4738-4799

claudiac.paulaeinsten@gmail.com
Received: 09/07/2020

Approved: 22/10/2020
Referencing this:

SANTOS, R. A.; BALDUINO, Â. R.; PAULA, C. C.. Válvulas redutoras de ar nos sistemas de micromedição nas redes de distribuição de água. Natural Resources, v.10, n.3, p.77-86, 2020. DOI: http://doi.org/10.6008/CBPC2237-9290.2020.003.0009 


\section{INTRODUÇÃO}

Sempre foi preocupação de todos os povos, em todas as épocas, o abastecimento de água para o consumo humano. Desde a antiguidade as civilizações sempre faziam suas casas e suas plantações próximos aos cursos de água, visto que, sem água, a vida humana não existiria, pois $70 \%$ da estrutura corporal humana é constituída por água. Diversos documentos históricos que contam um pouco da vida a milhões de anos atrás, atestam a preocupação do homem em abastecer de água o seu grupo. Exemplo disso é no tempo da Roma dos Césares, onde foram construídas várias obras hidráulicas com o intuito de abastecer os integrantes daquela sociedade (CREDER, 2006).

O processo de abastecimento e distribuição de água é considerado um sistema de conjuntos formados por partes. Onde, cada uma das partes tem um objetivo e/ou função, correspondendo aos órgãos compostos por obras de construção civil, equipamentos elétricos e eletrônicos, acessórios, instrumentação e equipamentos de automação e controle (SOUSA, 2001).

A distribuição da água em alguns pontos ou em determinados horários chega ao consumidor de maneira insatisfatória, outras vezes acaba nem chegando por falta de pressão (m.c.a), ou por outros problemas na rede de distribuição. Sendo que, segunda a NBR 12218 (ABNT, 1994), o mínimo de pressão que a água deve chegar às torneiras dos clientes é de 10 (m.c.a) e o máximo é de 50 (m.c.a), independente da altitude dos pontos e do horário.

De acordo com Favretto et al. (2016), as deficiências operacionais nas redes de abastecimento de água, são originadas pela falha de projeção do crescimento populacional dos munícipios, necessidade de atendimento de alta demanda, ou pela falta de manutenção adequada na rede de distribuição. Para Silva et al. (2003), tanto nos setores de abastecimento, quanto nos sistemas produtores, no conjunto de abastecimento de água a macromedição é um combo de medições. Esse composto engloba a medição da água bruta captada, entrada nos setores de abastecimento e a água tratada entregue por atacado a outros sistemas públicos.

Dentro da macromedição, a micromedição tem a finalidade de fornecer informações importantes no tocante a saúde financeira das companhias de distribuição de água, é o volume medido para ser transformado em volume faturado. A micromedição está na ponta do processo no sistema de medições, sendo um instrumento de grande importância para o uso racional da água (SÁ, 2007).

Alguns fatores podem estar ligados ao aumento significativo na conta mensal de água em algumas partes do sistema de abastecimento. Alguns destes fatores são como por exemplo, vazamentos, condições de trabalho impróprias para o aparelho de medição, fugas de água ou a presença de ar nas tubulações. $\mathrm{O}$ ar na maioria das vezes pode estar presente da rede de distribuição de água, ou em até mesmo em bolsões de ar no sistema, que podem ter sido inseridos no momento da manutenção, ou por algum processo involuntário na estação de tratamento (ETE) (MIRANDA, 2011).

Para Lopes et al. (2011), no Brasil, o volume de ar medido pelos hidrômetros tem causado uma controvérsia, e com isso tem despertado a atenção dos técnicos para esta questão de que o ar afluente nas 
redes de distribuição de água é contabilizado nos hidrômetros no momento da passagem dele. Diante dessa questão, algumas investigações relacionadas a este fato foram encomendadas pelos prestadores de serviços de abastecimento de água, onde, as tais pesquisas são voltadas exclusivamente aos equipamentos eliminadores de ar.

Ainda segundo os autores, alguns setores e organizações mostraram interesse por equipamentos que eliminem o ar na medição nos hidrômetros. Um exemplo de um aparelho desses denominado de eliminador de ar, teve seu surgimento no ano de 1991, tendo o mesmo mecanismo de funcionamento de uma ventosa simples. Tal equipamento segundo os fabricantes oferece até $35 \%$ de redução na conta de água. 0 outro equipamento que auxilia na redução da medição do ar nos hidrômetros é o bloqueador de ar, onde este é instalado depois dos aparelhos de medição, ou seja, já dentro da residência dos consumidores, sendo assim não há restrição por parte das empresas responsáveis pelo tratamento e distribuição da água. 0 princípio de funcionamento deste aparelho se baseia, segundo o fabricante, pela diferença de pressão ar-água, possibilitando a identificação do fluído.

Atentando para as imprecisões por parte dos sistemas de abastecimento de água, no que se refere o quesito da micromedição, onde os hidrômetros fazem medições imprecisas em relação ao real consumo do volume de água de cada cliente e, pelo o motivo de haver ar nos seus sistemas, é de suma importância a realização desse estudo, onde o mesmo vai acentuar sobre a medição do ar nos sistemas de micromedição, avaliando se as válvulas redutoras de ar podem intervir com mudanças nessas medições, se tornando um aparelho útil que acarreta melhorias, segurança e uma medição do volume de água justa. Objetivando analisar a interferência do ar na micromedição, verificando a eficácia das válvulas redutoras de ar como aparelhos que possam extinguir ou minimizar a passagem do ar no hidrômetro.

\section{MATERIAIS E MÉTODOS}

Para evitar erros, medições e leituras imprecisas, o projeto de pesquisa foi dividido em duas etapas, onde a primeira realizou testes de precisão nos dois hidrômetros utilizados nos ensaios. Foram submetidos a testes de precisão dois hidrômetros novos de marcas e modelos iguais do tipo multijato velocimétrico classe B com (Qn) vazão nominal de 1,5 m³ $/ \mathrm{h}$, como apresentado na figura 1.

Para realização dos testes nos medidores (hidrômetros) foi utilizado uma bancada para experimentos da marca Labtrix modelo MF-03, disponível no laboratório de mecânica dos fluidos do Instituto Tocantinense Antônio Carlos - Porto Nacional (ITPAC), a mesma é constituída de reservatório com escala graduada em milímetros, bombas hidráulicas, manômetros medidores de pressão, tubulações e hidrômetro residencial com selo do INMETRO portaria no 246 de 17/10/2000 (figura 2).

Os hidrômetros foram testados checando se os mesmos apresentavam alguma imprecisão na medição de consumo, que poderia interferir nos resultados quando a válvula redutora de ar for instalada. Foram realizadas leituras com a pressão de 10 (m.c.a), o ideal para condições normais da rede de abastecimento e vazão de $1,3 \mathrm{~m}^{3} / \mathrm{h}$ próximo ao (Qn) vazão nominal de funcionamento dos medidores aferidos que é de $1,5 \mathrm{~m}^{3} / \mathrm{h}$. Para execução desta parte do projeto de pesquisa, foi necessário materiais usuais 
em redes de água domiciliar tais como: Hidrômetro com vazão conhecida obedecendo às condições da portaria 246/2000 do INMETRO; Reservatório simulado de água; Tubos e conexões de pvc; e Manômetros.

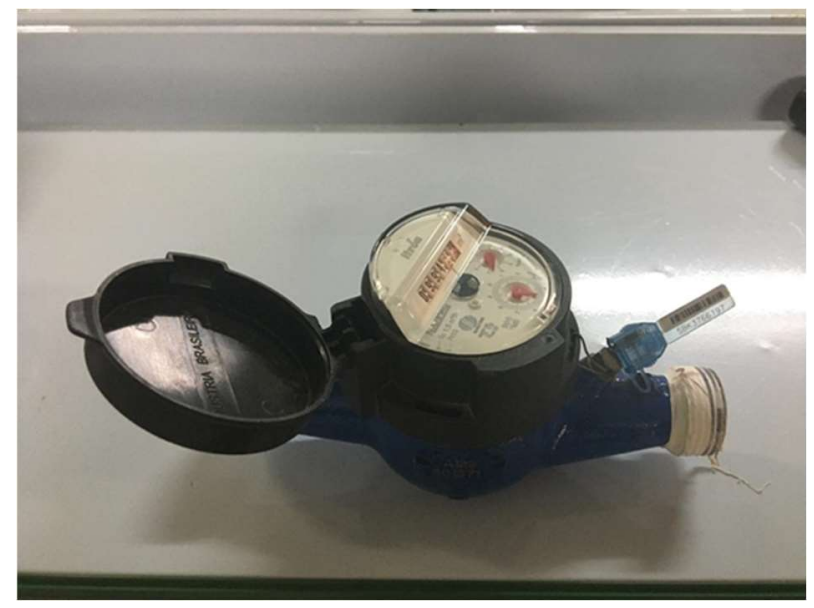

Figura 1: hidrômetro do tipo multijato velocimétrico classe B com (Qn) vazão nominal de $1,5 \mathrm{~m}^{3} / \mathrm{h}$.

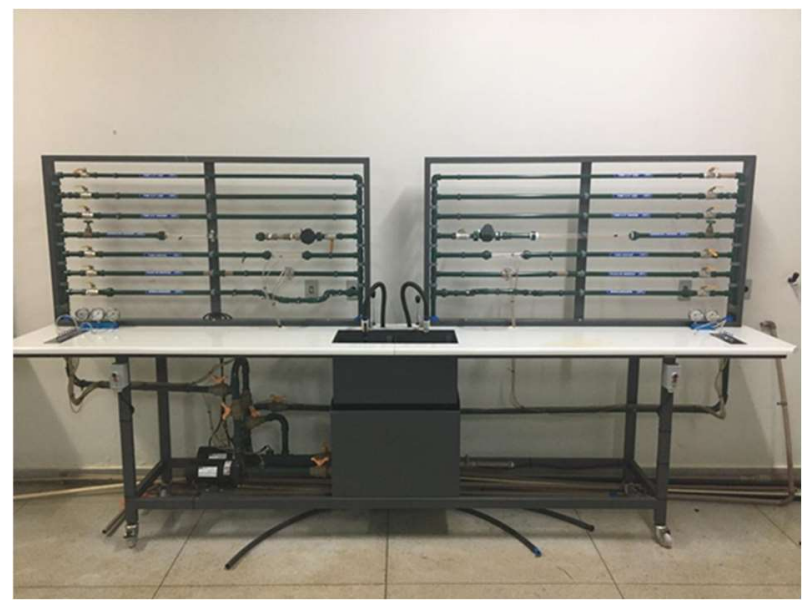

Figura 2: Bancada Labtrix modelo MF-03.

A segunda etapa do projeto foi a instalação e verificação do funcionamento da válvula redutora de ar no sistema, para isso foi montada no laboratório de hidráulica do ITPAC PORTO, uma rede de água para consumo que se aproxime ao máximo da realidade cotidiana de uma residência comum, o ramal foi instalado com medidor de consumo devidamente aferido e após o mesmo instalado um bloqueador de ar a jusante do hidrômetro conforme orientação do fabricante, o ramal foi submetido a testes em condições normais de abastecimento sem ar na rede, e com a presença de ar, que foi injetado na rede através de um compressor de ar comprimido. As leituras foram realizadas de modo que a rede esteve operando com a presença de arágua, somente ar e somente água, durante as leituras foi instalado dois hidrômetros um sobe a influência do ar e o outro sem a influência do ar ambos a montante do bloqueador de modo que possa ser checado a sua eficiência em relação ao seu ponto de instalação na rede. Os materiais utilizados nesta etapa são os mesmos da etapa anterior, com exceção do acréscimo do aparelho compressor de ar comprimido que simula a injeção de ar no sistema, conforme apresentado na figura 3.

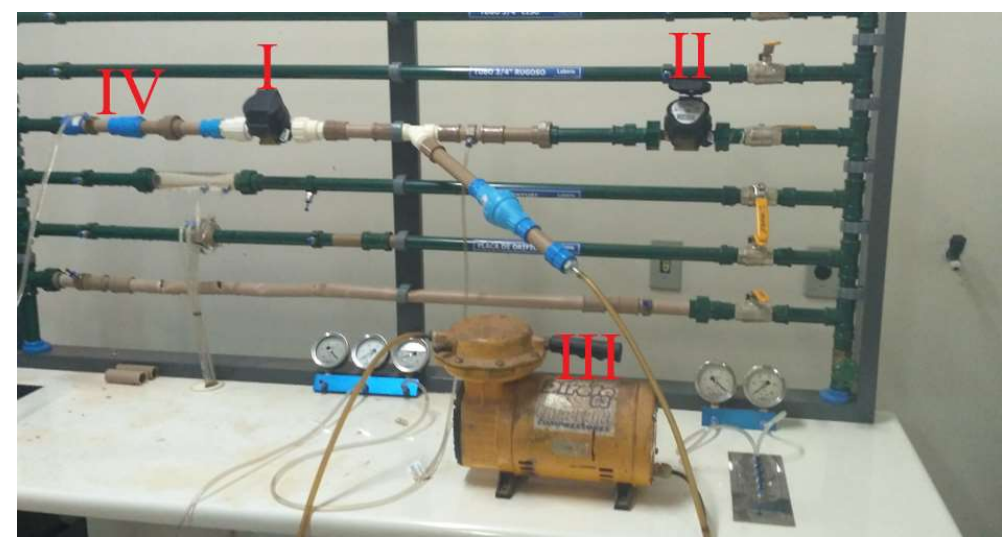

Figura 3: Esquema do ramal para teste com as Válvulas Redutoras de Ar. I) e II) hidrômetros, III) compressor de ar comprimido e IV) válvula redutora de ar.

\section{RESULTADOS}

Como resultado da primeira etapa do projeto, no teste de precisão os hidrômetros foram ligados em 
serie e submetidos a mesma vazão e pressão, ao qual ambos após o tempo de 5 minutos de funcionamento apresentaram o mesmo volume medido de 110 litros de água, tabela 1.

Tabela 1: Teste de precisão dos hidrômetros apenas com a injeção de água no sistema.

\begin{tabular}{|c|c|c|c|c|c|c|c|c|}
\hline \multicolumn{9}{|c|}{ TESTE DE PRECISÃO DOS HIDRÔMETROS (SOMENTE ÁGUA) } \\
\hline \multirow[t]{2}{*}{ HIDRÔMETRO I } & CLASSE & $\begin{array}{l}\text { (Qn) } \\
\text { VAZÃO } \\
\text { NOMINAL }\end{array}$ & $\begin{array}{l}\text { (Qn) } \\
\text { VAZÃO } \\
\text { TESTE }\end{array}$ & PRESSÃO & $\begin{array}{l}\text { TEMPO } \\
\text { DE } \\
\text { MEDIÇÃO }\end{array}$ & $\begin{array}{l}\text { LEITURA } \\
\text { INICIAL }\end{array}$ & $\begin{array}{l}\text { LEITURA } \\
\text { FINAL }\end{array}$ & $\begin{array}{l}\text { VOLUME } \\
\text { MEDIDO } \\
\text { (Água) }\end{array}$ \\
\hline & B & $\begin{array}{l}1,5 \\
\left(\mathrm{~m}^{3} / \mathrm{h}\right)\end{array}$ & $\begin{array}{l}1,3 \\
\left(\mathrm{~m}^{3} / \mathrm{h}\right)\end{array}$ & $\begin{array}{l}10 \\
\text { (m.c.a) }\end{array}$ & $\begin{array}{l}5 \\
\text { (minutos) }\end{array}$ & 10,0988 & 10,2087 & $\begin{array}{l}110 \\
\text { (litros) }\end{array}$ \\
\hline \multirow[t]{2}{*}{ HIDRÔMETRO II } & CLASSE & $\begin{array}{l}\text { (Qn) } \\
\text { VAZÃO } \\
\text { NOMINAL }\end{array}$ & $\begin{array}{l}\text { (Qn) } \\
\text { VAZÃO } \\
\text { TESTE }\end{array}$ & PRESSÃO & $\begin{array}{l}\text { TEMPO } \\
\text { DE } \\
\text { MEDIÇÃO }\end{array}$ & $\begin{array}{l}\text { LEITURA } \\
\text { INICIAL }\end{array}$ & $\begin{array}{l}\text { LEITURA } \\
\text { FINAL }\end{array}$ & $\begin{array}{l}\text { VOLUME } \\
\text { MEDIDO } \\
\text { (Água) }\end{array}$ \\
\hline & B & $\begin{array}{l}1,5 \\
\left(\mathrm{~m}^{3} / \mathrm{h}\right)\end{array}$ & $\begin{array}{l}1,3 \\
\left(\mathrm{~m}^{3} / \mathrm{h}\right)\end{array}$ & $\begin{array}{l}10 \\
\text { (m.c.a) }\end{array}$ & $\begin{array}{l}5 \\
\text { (minutos) }\end{array}$ & 15,5404 & 16,6510 & $\begin{array}{l}110 \\
\text { (litros) }\end{array}$ \\
\hline
\end{tabular}

Qn: vazão, $\mathrm{m}^{3} / \mathrm{h}$ : metros cúbicos por hora, m.c.a: metros de coluna d'água.

Na segunda etapa, com o intuito de checar se os hidrômetros operam somente com a presença de ar, foi realizado um teste inicial com hidrômetros instalados em série, estes foram submetidos à medição na bancada sobe baixa pressão de 3 (m.c.a) sem a instalação da válvula redutora de ar, o tempo de medição foi de 10 minutos injetando somente ar na rede em um ponto médio entre o medidor I e o medidor II, tabela 2.

Tabela 2: Teste de precisão dos hidrômetros apenas com a injeção de Ar no sistema.

\begin{tabular}{|c|c|c|c|c|c|c|}
\hline \multirow[t]{2}{*}{ HIDRÔMETRO I } & $\begin{array}{l}\text { (Qn) } \\
\text { VAZÃO } \\
\text { TESTE }\end{array}$ & PRESSÃO & $\begin{array}{l}\text { TEMPO } \\
\text { DE } \\
\text { MEDIÇÃO }\end{array}$ & $\begin{array}{l}\text { LEITURA } \\
\text { INICIAL }\end{array}$ & $\begin{array}{l}\text { LEITURA } \\
\text { FINAL }\end{array}$ & $\begin{array}{l}\text { VOLUME } \\
\text { MEDIDO } \\
\text { (Ár) }\end{array}$ \\
\hline & $\begin{array}{l}, 34 \\
\left(\mathrm{~m}^{3} / \mathrm{h}\right)\end{array}$ & $\begin{array}{l}3 \\
\text { (m.c.a) }\end{array}$ & $\begin{array}{l}10 \\
\text { (minutos) }\end{array}$ & 15,9969 & 15,9969 & $\begin{array}{l}0 \\
\text { (litros) }\end{array}$ \\
\hline \multirow[t]{2}{*}{ HIDRÔMETRO II } & $\begin{array}{l}\text { (Qn) } \\
\text { VAZÃO } \\
\text { TESTE }\end{array}$ & PRESSÃO & $\begin{array}{l}\text { TEMPO } \\
\text { DE } \\
\text { MEDIÇÃO }\end{array}$ & $\begin{array}{l}\text { LEITURA } \\
\text { INICIAL }\end{array}$ & $\begin{array}{l}\text { LEITURA } \\
\text { FINAL }\end{array}$ & $\begin{array}{l}\text { VOLUME } \\
\text { MEDIDO } \\
\text { (Ár) }\end{array}$ \\
\hline & $\begin{array}{l}5,34 \\
\left(\mathrm{~m}^{3} / \mathrm{h}\right)\end{array}$ & $\begin{array}{l}3 \\
\text { (m.c.a) }\end{array}$ & $\begin{array}{l}10 \\
\text { (minutos) }\end{array}$ & 10,6867 & 11,5786 & $\begin{array}{l}891 \\
\text { (litros) }\end{array}$ \\
\hline
\end{tabular}

Qn: vazão, $\mathrm{m}^{3} / \mathrm{h}$ : metros cúbicos por hora, m.c.a: metros de coluna d'água.

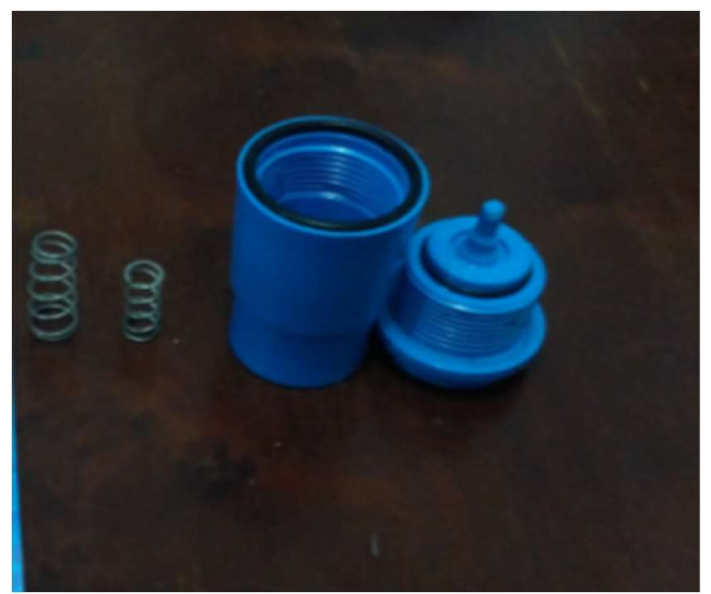

Figura 4: Válvula redutora de Ar com duas molas de diferentes tamanhos incluso.

Para os testes das válvulas, foi utilizada peça de marca mais vendida no mercado, a válvula da marca $\mathrm{X}$ cuja embalagem do fabricante diz prometer bloquear totalmente o ar, o dispositivo vem com duas molas uma menor com cerca de 2,0 cm de comprimento, e uma outra maior com cerca de 2,7 cm, essa mola serve como uma espécie de regulagem caso o ponto de instalação da mesma seja em um local que opera com baixa 
pressão, a mola maior segundo o manual de instalação do fabricante possibilita o funcionamento eficiente do bloqueador em locais com pouquíssima pressão, figura 4.

O bloqueador da marca $\mathrm{X}$ foi submetido a ensaios introduzindo somente ar na rede, utilizando as duas molas que vem no kit de instalação os resultados podem ser analisados conforme as tabelas 3 e 4 .

Tabela 3: Medição somente com Ar na rede com a válvula e usando a mola grande de $2,7 \mathrm{~cm}$.

\begin{tabular}{|c|c|c|c|c|c|c|}
\hline \multicolumn{7}{|c|}{ MEDIÇÃO SOMENTE AR NA REDE COM A VÁLVULA MOLA GRANDE } \\
\hline \multirow[t]{2}{*}{ HIDRÔMETRO I } & \begin{tabular}{|l} 
(Qn) \\
VAZÃO \\
TESTE \\
\end{tabular} & PRESSÃO & $\begin{array}{l}\text { TEMPO } \\
\text { DE } \\
\text { MEDIÇÃO }\end{array}$ & $\begin{array}{l}\text { LEITURA } \\
\text { INICIAL }\end{array}$ & $\begin{array}{l}\text { LEITURA } \\
\text { FINAL }\end{array}$ & $\begin{array}{l}\text { VOLUME } \\
\text { MEDIDO } \\
\text { (Ár) }\end{array}$ \\
\hline & $\begin{array}{l}0,00 \\
\left(\mathrm{~m}^{3} / \mathrm{h}\right)\end{array}$ & $\begin{array}{l}0 \\
\text { (m.c.a) }\end{array}$ & $\begin{array}{l}10 \\
\text { (minutos) }\end{array}$ & 17,0469 & 17,0469 & $\begin{array}{l}0 \\
\text { (litros) }\end{array}$ \\
\hline \multirow{2}{*}{ HIDRÔMETRO II } & $\begin{array}{l}\text { (Qn) } \\
\text { VAZÃO } \\
\text { TESTE }\end{array}$ & PRESSÃO & $\begin{array}{l}\text { TEMPO } \\
\text { DE } \\
\text { MEDIÇÃO }\end{array}$ & $\begin{array}{l}\text { LEITURA } \\
\text { INICIAL }\end{array}$ & $\begin{array}{l}\text { LEITURA } \\
\text { FINAL }\end{array}$ & $\begin{array}{l}\text { VOLUME } \\
\text { MEDIDO } \\
\text { (Ár) }\end{array}$ \\
\hline & \begin{tabular}{|l|}
4,44 \\
$\left(\mathrm{~m}^{3} / \mathrm{h}\right)$
\end{tabular} & $\begin{array}{l}3 \\
\text { (m.c.a) }\end{array}$ & $\begin{array}{l}10 \\
\text { (minutos) }\end{array}$ & 12,1056 & 12,8463 & $\begin{array}{l}740 \\
\text { (litros) }\end{array}$ \\
\hline
\end{tabular}

Qn: vazão, $\mathrm{m}^{3} / \mathrm{h}$ : metros cúbicos por hora, m.c.a: metros de coluna d'água.

Tabela 4: Medição somente com Ar na rede com a válvula e usando a mola pequena de $2,0 \mathrm{~cm}$.

\begin{tabular}{|c|c|c|c|c|c|c|}
\hline \multicolumn{7}{|c|}{ MEDIÇÃO SOMENTE AR NA REDE COM A VÁLVULA MOLA MENOR } \\
\hline \multirow{4}{*}{ HIDRÔMETRO I } & (Qn) & & TEMPO & & & VOLUME \\
\hline & VAZÃO & PRESSÃO & & LEITURA & LEITURA & MEDIDO \\
\hline & TESTE & & MEDIÇÃO & & & (Ár) \\
\hline & $\begin{array}{l}0,00 \\
\left(\mathrm{~m}^{3} / \mathrm{h}\right)\end{array}$ & $\begin{array}{l}0 \\
\text { (m.c.a) }\end{array}$ & $\begin{array}{l}10 \\
\text { (minutos) }\end{array}$ & 17,0469 & 17,0469 & $\begin{array}{l}0 \\
\text { (litros) }\end{array}$ \\
\hline \multirow{4}{*}{ HIDRÔMETRO II } & (Qn) & & TEMPO & & & VOLUME \\
\hline & VAZÃO & PRESSÃO & & LEIIURA & LEIIURA & MEDIDO \\
\hline & TESTE & & MEDIÇÃO & & & (Ár) \\
\hline & $\begin{array}{l}2,91 \\
\left(\mathrm{~m}^{3} / \mathrm{h}\right)\end{array}$ & $\begin{array}{l}8 \\
\text { (m.c.a) }\end{array}$ & $\begin{array}{l}10 \\
\text { (minutos) }\end{array}$ & 12,8463 & 13,3331 & $\begin{array}{l}486 \\
\text { (litros) }\end{array}$ \\
\hline
\end{tabular}

Qn: vazão, $\mathrm{m}^{3} / \mathrm{h}$ : metros cúbicos por hora, m.c.a: metros de coluna d'água.

Para realização dos ensaios com a presença de ar mais água utilizando no ramal a válvula redutora de ar da marca Marca X, na entrada de ar de modo a se prevenir o golpe de aríete, foi usada uma junção em ' $Y$ ' rosqueavél, o que de fato evitou o fenômeno, figura 3. Os resultados para o ensaio são demonstrados na tabela 5 a instalação da válvula da marca Marca X foi realizada com a mola de menor comprimento que exige uma maior pressão de funcionamento da rede.

Tabela 5: Medição com Ar+Água na rede com a válvula e usando a mola pequena de 2,0 cm.

\begin{tabular}{|c|c|c|c|c|c|c|c|}
\hline \multicolumn{8}{|c|}{ MEDIÇÃO AR+ÁGUA COM VÁLVULA MARCA X E MOLA MENOR } \\
\hline \multirow{4}{*}{ HIDRÔMETRO I } & MEDIÇÃO & $\begin{array}{l}\text { (Qn) } \\
\text { VAZÃO } \\
\text { TESTE }\end{array}$ & PRESSÃO & $\begin{array}{l}\text { TEMPO } \\
\text { DE } \\
\text { MEDIÇÃO }\end{array}$ & $\begin{array}{l}\text { LEITURA } \\
\text { INICIAL }\end{array}$ & $\begin{array}{l}\text { LEITURA } \\
\text { FINAL }\end{array}$ & $\begin{array}{l}\text { VOLUME } \\
\text { MEDIDO } \\
\text { (Água) }\end{array}$ \\
\hline & 1 & $\begin{array}{l}0,64 \\
\left(\mathrm{~m}^{3} / \mathrm{h}\right)\end{array}$ & $\begin{array}{l}15 \\
\text { (m.c.a) }\end{array}$ & $\begin{array}{l}10 \\
\text { (minutos) }\end{array}$ & 17,6556 & 17,7629 & $\begin{array}{l}107 \\
\text { (litros) }\end{array}$ \\
\hline & 2 & $\begin{array}{l}0,38 \\
\left(\mathrm{~m}^{3} / \mathrm{h}\right)\end{array}$ & $\begin{array}{l}10 \\
\text { (m.c.a) }\end{array}$ & $\begin{array}{l}10 \\
\text { (minutos) }\end{array}$ & 17,7655 & 17,8297 & $\begin{array}{l}64 \\
\text { (litros) }\end{array}$ \\
\hline & 3 & $\begin{array}{l}0,06 \\
\left(\mathrm{~m}^{3} / \mathrm{h}\right)\end{array}$ & $\begin{array}{l}5 \\
\text { (m.c.a) }\end{array}$ & $\begin{array}{l}10 \\
\text { (minutos) }\end{array}$ & 17,8379 & 17,8470 & $\begin{array}{l}10 \\
\text { (litros) }\end{array}$ \\
\hline \multirow{4}{*}{ HIDRÔMETRO II } & MEDIÇÃO & $\begin{array}{l}\text { (Qn) } \\
\text { VAZÃO } \\
\text { TESTE } \\
\end{array}$ & PRESSÃO & $\begin{array}{l}\text { TEMPO } \\
\text { DE } \\
\text { MEDIÇÃO }\end{array}$ & $\begin{array}{l}\text { LEITURA } \\
\text { INICIAL }\end{array}$ & $\begin{array}{l}\text { LEITURA } \\
\text { FINAL }\end{array}$ & $\begin{array}{l}\text { VOLUME } \\
\text { MEDIDO } \\
\text { (Ar+Água) }\end{array}$ \\
\hline & 1 & $\begin{array}{l}1,61 \\
\left(\mathrm{~m}^{3} / \mathrm{h}\right)\end{array}$ & $\begin{array}{l}15 \\
\text { (m.c.a) }\end{array}$ & $\begin{array}{l}10 \\
\text { (minutos) }\end{array}$ & 16,2557 & 16,5252 & $\begin{array}{l}269 \\
\text { (litros) }\end{array}$ \\
\hline & 2 & $\begin{array}{l}0,94 \\
\left(\mathrm{~m}^{3} / \mathrm{h}\right)\end{array}$ & $\begin{array}{l}10 \\
\text { (m.c.a) }\end{array}$ & $\begin{array}{l}10 \\
\text { (minutos) }\end{array}$ & 16,7021 & 16,5439 & $\begin{array}{l}158 \\
\text { (litros) }\end{array}$ \\
\hline & 3 & 0,90 & 5 & 10 & 16,7326 & 16,8760 & 143 \\
\hline
\end{tabular}




$$
\left(\mathrm{m}^{3} / \mathrm{h}\right) \quad \text { (m.c.a) (minutos) }
$$

(litros)

Qn: vazão, $\mathrm{m}^{3} / \mathrm{h}$ : metros cúbicos por hora, m.c.a: metros de coluna d'água.

Como o dispositivo da marca Marca X possui duas molas para regulagem foram repetidas as mesmas medições com o dispositivo, porém com a mola maior instalada em seu interior, para comparação dos dados obtidos, foram utilizadas as mesmas pressões de 15, 10 e 5 m.c.a, em que as leituras obtidas são demonstradas na tabela 6.

Tabela 6: Medição com Ar+Água na rede com a válvula e usando a mola grande de $2,7 \mathrm{~cm}$.

\begin{tabular}{|c|c|c|c|c|c|c|c|}
\hline \multicolumn{8}{|c|}{ MEDIÇÃO AR+ÁGUA COM VÁLVULA MARCA X E MOLA MAIOR } \\
\hline \multirow{4}{*}{ HIDRÔMETRO I } & MEDIÇÃO & $\begin{array}{l}\text { (Qn) } \\
\text { VAZÃO } \\
\text { TESTE }\end{array}$ & PRESSÃO & $\begin{array}{l}\text { TEMPO } \\
\text { DE } \\
\text { MEDIÇÃO }\end{array}$ & $\begin{array}{l}\text { LEITURA } \\
\text { INICIAL }\end{array}$ & $\begin{array}{l}\text { LEITURA } \\
\text { FINAL }\end{array}$ & $\begin{array}{l}\text { VOLUME } \\
\text { MEDIDO } \\
\text { (Água) }\end{array}$ \\
\hline & 1 & $\begin{array}{l}1,57 \\
\left(\mathrm{~m}^{3} / \mathrm{h}\right)\end{array}$ & $\begin{array}{l}15 \\
\text { (m.c.a) }\end{array}$ & $\begin{array}{l}10 \\
\text { (minutos) }\end{array}$ & 17,8594 & 18,1221 & $\begin{array}{l}262 \\
\text { (litros) }\end{array}$ \\
\hline & 2 & $\begin{array}{l}0,85 \\
\left(\mathrm{~m}^{3} / \mathrm{h}\right)\end{array}$ & $\begin{array}{l}10 \\
\text { (m.c.a) }\end{array}$ & $\begin{array}{l}10 \\
\text { (minutos) }\end{array}$ & 18,1264 & 18,2960 & $\begin{array}{l}142 \\
\text { (litros) }\end{array}$ \\
\hline & 3 & $\begin{array}{l}0,25 \\
\left(\mathrm{~m}^{3} / \mathrm{h}\right) \\
\end{array}$ & $\begin{array}{l}5 \\
\text { (m.c.a) }\end{array}$ & $\begin{array}{l}10 \\
\text { (minutos) }\end{array}$ & 18,2788 & 18,3216 & $\begin{array}{l}42 \\
\text { (litros) }\end{array}$ \\
\hline \multirow{4}{*}{ HIDRÔMETRO II } & MEDIÇÃO & $\begin{array}{l}\text { (Qn) } \\
\text { VAZÃO } \\
\text { TESTE }\end{array}$ & PRESSÃO & $\begin{array}{l}\text { TEMPO } \\
\text { DE } \\
\text { MEDIÇÃO }\end{array}$ & $\begin{array}{l}\text { LEITURA } \\
\text { INICIAL }\end{array}$ & $\begin{array}{l}\text { LEITURA } \\
\text { FINAL }\end{array}$ & $\begin{array}{l}\text { VOLUME } \\
\text { MEDIDO } \\
\text { (Ar+Água) }\end{array}$ \\
\hline & 1 & $\begin{array}{l}3,89 \\
\left(\mathrm{~m}^{3} / \mathrm{h}\right)\end{array}$ & $\begin{array}{l}15 \\
\text { (m.c.a) }\end{array}$ & $\begin{array}{l}10 \\
\text { (minutos) }\end{array}$ & 16,8910 & 17,4901 & $\begin{array}{l}649 \\
\text { (litros) }\end{array}$ \\
\hline & 2 & $\begin{array}{l}2,58 \\
\left(\mathrm{~m}^{3} / \mathrm{h}\right)\end{array}$ & $\begin{array}{l}10 \\
\text { (m.c.a) }\end{array}$ & $\begin{array}{l}10 \\
\text { (minutos) }\end{array}$ & 17,5056 & 17,9364 & $\begin{array}{l}430 \\
\text { (litros) }\end{array}$ \\
\hline & 3 & $\begin{array}{l}1,23 \\
\left(\mathrm{~m}^{3} / \mathrm{h}\right)\end{array}$ & $\begin{array}{l}5 \\
\text { (m.c.a) }\end{array}$ & $\begin{array}{l}10 \\
\text { (minutos) }\end{array}$ & 17,9596 & 18,1653 & $\begin{array}{l}205 \\
\text { (litros) }\end{array}$ \\
\hline
\end{tabular}

Qn: vazão, $\mathrm{m}^{3} / \mathrm{h}$ : metros cúbicos por hora, m.c.a: metros de coluna d'água.

\section{DISCUSSÃO}

Segundo Santos et al. (2014), desde a água que chega à residência dos consumidores até a sua capitação existem perdas, assim como em praticamente todos os sistemas de abastecimento existentes nas cidades brasileiras. Essa questão resulta numa operação dos sistemas com o custo bem elevado, gerando assim prejuízos no faturamento.

Para AWWA (1986) e Gularte (2005), a inexistência de uma política de micromedição adequada pode constituir-se em um dos fatores responsáveis pela ineficiência operacional e comercial de uma empresa de saneamento básico, no entanto, uma micromedição eficiente, não se resume apenas à aquisição, instalação ou troca de hidrômetros.

O experimento obteve dados analíticos submetendo o ramal montado a diferentes testes de pressão e vazão, em diversas situações de funcionamento, as medições realizadas foram feitas utilizando dois medidores de mesma classe e Qn vazão nominal, cujo quais não apresentaram nenhuma imprecisão quando aferidos na bancada de testes.

Conforme a tabela 2 o hidrômetro I não registrou nenhum volume de ar ao contrário do hidrômetro Il que mediu 891 litros de ar em 10 minutos sob uma baixa pressão de 3 m.c.a e com uma vazão de 5,34 m³/h, isso se deu devido ao local de entrada do ar que foi instalado em um ponto médio entre ambos os medidores, nessa medição o medidor I foi instalado apenas como parâmetro de observação caso ocorresse o fluxo inverso do ar injetado pelo compressor, o que não aconteceu. Fica claro que os medidores trabalham e 
funcionam quando submetidos somente a ação do ar mesmo em baixa pressão.

Nos testes realizados apenas com a presença de ar na rede com a válvula da marca Marca X, tabelas 3 e 4, mesmo em baixa pressão ouve a medição do ar que passava pelo hidrômetro Il, o volume de ar medido foi mais elevado com a mola de maior comprimento instalada, onde se percebeu que a mola de menor comprimento, que também vem no kit de instalação, opera de forma que a rede necessite de uma maior pressão de funcionamento, quando a pressão é muito baixa 3 m.c.a a válvula impede totalmente a passagem do ar, no entanto caso haja variação positiva de pressão o ar vai passar pelo hidrômetro e ser contabilizado, para a mola de maior comprimento a pressão crítica foi estabelecida no ensaio em 5 m.c.a, para a mola de menor comprimento que exige uma pressão de funcionamento mais elevada a pressão crítica foi estabelecida em 8 m.c.a, a partir desses valores de pressão do ar consegue passar pelo hidrômetro e pelo bloqueador da Marca X.

Para o ensaio com a presença de ar mais água utilizando a válvula Marca X, tabela 5, o hidrômetro I, serviu de parâmetro para comparação dos volumes medidos no hidrômetro II, a válvula foi posicionada na rede de acordo as especificações do fabricante que orienta instalar o dispositivo após o hidrômetro, nos testes realizados com a válvula foram feitas medições com pressões de 15, 10 e 5 m.c.a, verificado a vazão e o volume de água medido no primeiro medidor que não estava sob a influência do ar e no segundo medidor sob a ação do ar, ou seja, o primeiro mediu apenas água. As medições demonstram que os valores obtidos no hidrômetro II são em toda totalidade superiores aos valores obtidos no medidor I, observou-se que o medidor II contabilizou tanto o ar quanto a água mesmo com o dispositivo instalado, o que chamou a atenção foi que mesmo havendo a presença de ar e água na rede com 5 m.c.a, o fluxo era interrompido passando apenas o ar pelo bloqueador, outro fato foi o aumento da vazão no hidrômetro II isso se deu por este estar sob a influência do ar injetado pelo compressor em um ponto médio entre o medidor I e II.

De acordo a portaria $\mathrm{n}^{\circ} 246$ de 17 de outubro de 2000 e os respectivos Regulamentos Técnicos Metrológico do INMETRO, que regulamenta legalmente a homologação de modelos, testes, verificações periódicas ou eventuais, bem como limites para manutenção e/ou troca dos medidores de água. Estabelece também as condições que, medidores de água fria de vazão nominal de $(0,6$ a 15$) \mathrm{m}^{3} / \mathrm{h}$, devem satisfazer as exigências da rede de distribuição de água.

O uso de hidrômetros se limita ao conhecimento dos volumes com fins de controle e faturamento, se bem que hoje em dia já há modelos que incorporam circuitos eletrônicos capazes de realizar funções adicionais, tais como, determinar vazões históricas, vazões de pico, tempo girando etc. Também existem modelos dotados de saídas de pulsos capazes de emitir um sinal elétrico cada vez que o totalizador contabiliza um volume determinado. Uma memória interna acumula os dados e o volume acumulado pode ser lido tanto no local como remotamente (GULARTE, 2005).

Nota-se na tabela 6 que quando o dispositivo foi submetido ao mesmo teste sob as mesmas condições de pressão, dessa vez com a mola de maior comprimento instalada em seu interior, houve um aumento do volume medido tanto no medidor I quanto no medidor II, apontando uma discrepância ainda mais elevada em relação aos volumes obtidos em ambos os medidores, o que ficou visível foi que houve uma 
passagem de ar ainda maior no medidor II, volume de ar este contabilizado novamente junto com a água. Verificou-se também que a vazão aumentou com a instalação do dispositivo com a mola de maior comprimento em ambos os medidores, sendo que novamente as maiores vazões foram registradas no medidor II, pois esse contabilizou tanto o ar como a água.

Gularte (2005) e Borges (2007) destacam que o hidrômetro durante seu uso na medição do consumo é submetido a diferentes valores de vazão, em função das características de uso nos pontos de consumo. Este fator está intimamente ligado aos erros de medição desses aparelhos. Werdine (2002) implica que é importante a relação estabelecida entre as empresas de saneamento básico e o consumidor, uma vez caracterizado imprecisões nas medições de consumo como cobranças indevidas, isso poderá vir a afetar a credibilidade no sistema, e gerar questionamentos como a discussão a respeito de volumes de ar contabilizados nos medidores e faturados como água.

Em análise aos dados obtidos nas três medições realizadas sob pressões diferentes em ambas as molas, observou-se que o funcionamento do dispositivo se dá em relação a pressão exercida na rede, os valores medidos diminuem em função da diminuição da pressão. Para Miranda (2011), a falta de legislação e normalização desse tipo de aparato torna seu funcionamento contestável uma vez que não há testes nem regulamentação que garanta o seu desempenho, como não há obrigatoriedade das companhias de instalar tais dispositivos o mesmo só pode ser instalado após o hidrômetro.

\section{CONCLUSÕES}

Os resultados das análises obtidas em laboratório foram satisfatórios visto que objetivo geral dessa pesquisa foi alcançado estabelecendo parâmetros sobre a presença do ar nas redes de abastecimento de água, concretizando a tese de que o ar uma vez presente na rede, e chegando até os medidores, poderá ocasionar imprecisões na micromedição, impactando diretamente em todo o sistema de abastecimento público da comunidade e nas relações de custos e faturamento dessas companhias.

Diante do exposto, conclui-se que a instalação das válvulas redutoras de ar não impede a passagem do ar nos aparelhos de medição (hidrômetros), e posteriormente a sua contabilização como se fosse água. A eficácia das válvulas estudadas depende da pressão de funcionamento da rede de distribuição, ou seja, quanto maior for a pressão menos eficiente o dispositivo se torna, e quando a pressão for muito baixa, estando no ponto crítico da válvula, pode ser que o fornecimento da água seja interrompido pois este aparelho exige que a pressão para o abastecimento normal do ramal esteja a partir de 10 m.c.a, em uma condição onde houver falta de água, um domicilio onde tenha o dispositivo instalado demorara um pouco mais de tempo para que o abastecimento volte ao normal.

Pelo fato de as válvulas não serem normalizadas pelos órgãos competentes não se recomenda o seu uso, pois como os testes demostraram, mesmo sob baixas pressões o dispositivo não impede a passagem do ar, e caso sejam instalados em locais de baixa pressão podem até mesmo interromper o abastecimento de água.

Com base nos resultados alcançados por este projeto de pesquisa, fica como sugestão às empresas 
de saneamento, que em seus projetos de rede de abastecimento de água, antecipem e instalem mais dispositivos que venham intervir com a influência negativa do ar na rede em todos os ramais de abastecimento, isso é um fator de suma importância para garantir uma medição de consumo mais precisa e justa, mantendo a eficiência do sistema e a satisfação de seus usuários.

\section{REFERÊNCIAS}

ABNT. Associação Brasileira de Normas Técnicas. NBR 12218/1994: Projeto de rede de distribuição de água para abastecimento público. ABNT, 1994.

AWWA. American Water Works Association. Water Meters: Selection, Installation, Testing and Maintenance: American Water Works Association. 3 ed. Denver: CO, 1986.

BORGES, E. J.. Analise da Micromedição do Volume de Água Potável Domiciliar e sua Influência no Cálculo das Perdas no Sistema de Distribuição. Dissertação (Mestrado em Engenharia Urbana) - Universidade Federal de Uberlândia, Uberlândia, 2007.

CREDER, H.. Instalações hidráulicas e sanitárias: Livros Técnicos e Científicos. 6 ed. Rio de Janeiro: LTC, 2006.

FAVRETTO, C. R.; SCHUMANN, C.; DALL'AGNOL, A. L. B.; NAZARI, M. T.; ARAUJO, M. M. F.; QUADRO, M. S.. Análise do sistema de abastecimento de água do município de Arroio do Padre/RS. In: ENCONTRO NACIONAL DE ESTUDANTES DE ENGENHARIA AMBIENTAL, 14. Anais. São Paulo: Blucher, 2016. DOI: https://doi.org/10.5151/engpro-eneeamb2016pogi-002-5063

GULARTE, C. B.. Um Estudo sobre a Submedição em Hidrômetros para Aplicação no Controle de Perdas Aparentes no Sistema de Abastecimento de Água de Blumenau. Dissertação (Mestrado em Metrologia) Universidade Federal de Santa Catarina, Florianópolis, 2005.

INMETRO. Instituto Nacional de Metrologia, Qualidade e Tecnologia. Portaria n. 246 de 17/10/2000. Aprova o Regulamento Técnico Metrológico para hidrômetros de água fria, de vazão nominal até 15 m³/h. Brasília: DOU, 2000.
LOPES, N. P.; LARA, M.; LIBÂNIO, M.. Quantificação em escala de bancada do volume de ar em ligações prediais de água. Engenharia Sanitária Ambiental, Rio de Janeiro, v.16, n.4, p.343-352, 2011. DOI: https://doi.org/10.1590/S141341522011000400005

MIRANDA, I. S. L.. Presença de Ar no Sistema de Abastecimento de Água: influências na macro e micromedição. Monografia (Bacharelado em Engenharia Civil) - Universidade Federal do Rio Grande Do Sul, Porto Alegre, 2011.

SÁ, C. C.. A importância da micromedição no combate às perdas de água: estudo da hidrometração da Companhia Águas de Joinville. Dissertação (Mestrado em Engenharia Ambiental) - Universidade Federal de Santa Catarina, Florianópolis 2007.

SANTOS, D. D.; MONTENEGRO, S. M. G. L.. Avaliação da metodologia para controle de perdas de água em rede de distribuição no Recife/PE. Revista DAE, Recife, v.197, n.1, p.56-80, 2014. DOI: http://dx.doi.org/10.4322/dae.2014.128

SILVA, B. O. C; MONTEIRO, C. O.; TORRES, C. G. V.; SHINZATO, E.; MOKARZEL, F. C.; GUIBOSHI, M.; PELLEGRINI, T. C.. Controle de Perdas de água em Sistemas de Distribuição. São Paulo: Escola Politécnica da Universidade de São Paulo, 2003.

SOUSA, E. R.. Noções sobre qualidade da água. Dissertação (Mestrado em Engenharia Civil) - Instituto Superior Técnico, Lisboa, 2001.

WERDINE, D.. Perdas de Água em Sistemas de Abastecimento. Dissertação (Mestrado em Engenharia de Energia) - Universidade Federal de Itajubá, Itajubá, 2002.

A CBPC - Companhia Brasileira de Produção Científica (CNPJ: 11.221.422/0001-03) detém os direitos materiais desta publicação. Os direitos referem-se à publicação do trabalho em qualquer parte do mundo, incluindo os direitos às renovações, expansões e disseminações da contribuição, bem como outros direitos subsidiários. Todos os trabalhos publicados eletronicamente poderão posteriormente ser publicados em coletâneas impressas sob coordenação da Sustenere Publishing, da Companhia Brasileira de Produção Científica e seus parceiros autorizados. Os (as) autores (as) preservam os direitos autorais, mas não têm permissão para a publicação da contribuição em outro meio, impresso ou digital, em português ou em tradução. 